\title{
ULTRASONIC BALL/WEDGE BONDING OF ALUMINIUM WIRES
}

\author{
C. J. DAWES, K. I. JOHNSON and M. H. SCOTT \\ The Welding Institute, Abington Hall, Abington, Cambridge, England CB1 $6 A L$
}

(Received February 13, 1980)

\begin{abstract}
The process of ball/wedge bonding and its advantages are described. A capacitor discharge technique for the formation of balls on 25 and $75 \mu \mathrm{m}$ diameter aluminium wires is discussed. Ultrasonic welding trials were carried out and the bonds subjected to pull tests with good results. Bonds of good strength were made between $25 \mu \mathrm{m}$ diameter $\mathrm{Al}-1 \% \mathrm{Si}$ wire and $\mathrm{Al}$ thin films, Pd-Au thick films and Au flashed Kovar.
\end{abstract}

\section{INTRODUCTION}

Fine gold or aluminium wires ( $25 \mu \mathrm{m}$ diameter) are generally used to make connections between active circuit chips and external circuitry. These wires are welded to the chips and circuitry by the relatively cool thermocompression (hot pressure) and ultrasonic solid phase welding techniques as the devices degrade when subjected to elevated temperatures $\left(>350^{\circ} \mathrm{C}\right)$. Ultrasonic welding is currently the more favoured technique as it can be used on both aluminium and gold wires and is generally accomplished without any external heating.

Two ultrasonic wire bonding techniques are currently used: wedge-wedge bonding aluminium wires and ball/wedge bonding gold wires. During wedge bonding of aluminium wires a wedge-shaped tool flattens the wire and forms a weld beneath this region. This has two main disadvantages: the wire can easily be overdeformed which may produce a weak joint, and, before making the second wedge bond, the wire can be led away only along the axis of the first joint. Ultrasonic ball bonding of gold wires has become increasingly popular in the last five years because these limitations are eliminated. A ball is formed on the end of the gold wire and this ball is then welded to the circuit using a capillary tool. Overdeformation of the ball does not reduce the wire cross-section and the welding condition is consequently more tolerant to process variables. The wire can also be led in any direction from the weld which facilitates automation and increases production rate when manually controlled welding is employed. Following the ball bond, a wedge bond is made using one edge of the capillary. Thus when interconnections are made using this technique, the ball bond is generally made to the solid state device, and the subsequent wedge bond to the external circuitry.

Although ball/wedge bonding has these advantages over wedge/wedge wire bonding, the technique has only been applied to gold wires where the ball is formed by melting the wire either in a hydrogen flame or by capacitor discharge between the wire and a tungsten electrode $(460 \mathrm{~V}, 2 \mu \mathrm{F})$. If it could be applied to aluminium wires it would have additional economic and reliability advantages because there would be no degradation of the aluminium chip metallisation. Brittle gold/aluminium intermetallic compounds would not form at the joint in such a monometallic aluminium wire/aluminium chip metallisation system.

The main difficulty in applying the ball bonding technique to aluminium wire has been that of forming the balls. A hydrogen flame is not suitable as the wire oxidises and the tenacious oxide film prevents the wire balling up. Similarly, grossly oxidised balls are obtained when the commercially available electrical discharge technique is used and the application of shielding gases to the work area gives unsuitable electrical discharges which do not cause the wire to melt. Previous workers ${ }^{1}$ have also attempted to form balls on aluminium wires by focused laser beam, microplasma torch and radiant heater, as well as by capacitor discharge but no success was achieved.

Because of the potential advantages of an aluminium ball/wedge wire interconnection technique the above methods for forming balls on aluminium 
wire were again reviewed and it has been found that the capacitor discharge technique could be used to give good quality balls under certain conditions, and that this technique could be employed for making aluminium wire ball/wedge welded interconnections. This paper describes the techniques employed for forming balls on 25 and $75 \mu \mathrm{m}$ diameter aluminium wires, the design of equipment which can be incorporated on a standard ultrasonic gold ball/wedge welding machine to enable aluminium ball/wedge bonding and the results of detailed bonding trials to thin film aluminium, thick film palladium-silver and gold flashed Kovar when using $25 \mu \mathrm{m}$ diameter $\mathrm{Al}-1 \% \mathrm{Si}$ wire.

\section{BALL FORMING}

Various capacitor discharge systems and a special transistor power source with wave shape control, were investigated to establish the effect of electric arc energy control on ball quality. The power sources were attached in turn to an experimental apparatus which simulated the wire feed operation of a bonding machine. The apparatus also had an integral electrode and gas cup assembly which enclosed the end of the $\mathrm{Al}$ wire during the ball forming operation. The shielding gases studied were $\mathrm{Ar}, \mathrm{Ar}+\mathrm{O}_{2}, \mathrm{He}, \mathrm{Ne}, \mathrm{Kr}$ and $\mathrm{Xe}$.

The most consistent balls were formed using a capacitor discharge power source with an Ar gas shield. A condition was established which produced ball diameters in the range of 2.2 to $2.5 \times$ the wire diameter. The ball quality was typical of that shown in Figure 1.

A capacitor discharge ball forming attachment suitable for aluminium wire has been incorporated

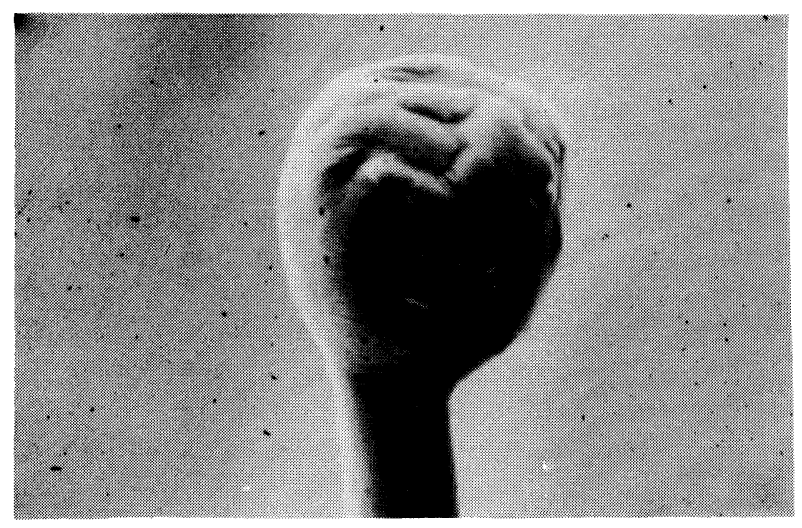

FIGURE 1 Good quality ball on $25 \mu$ m diameter aluminium wire.

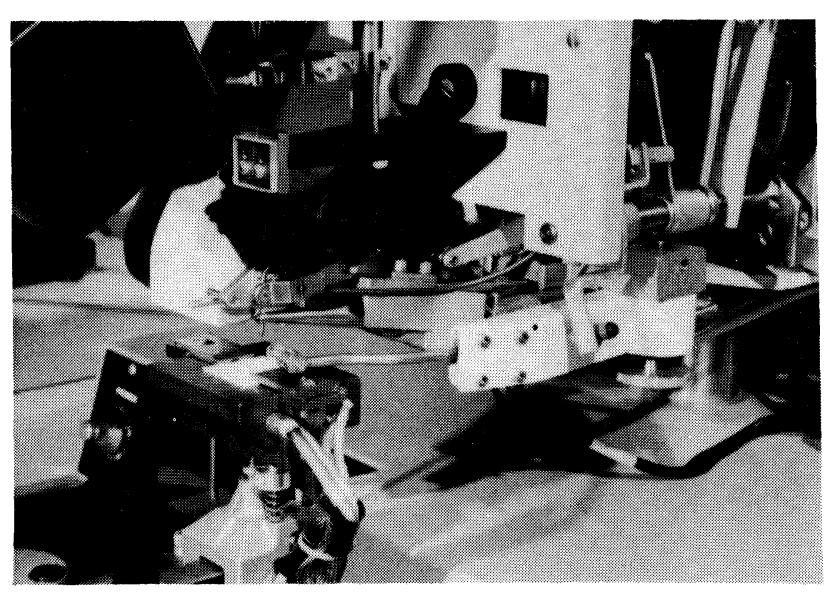

FIGURE 2 Ball forming attachment fitted to Kulicke \& Soffa 472 ball bonding machine.

on the Kulicke and Soffa 472 machine, see Figure 2. This replaced the hydrogen torch assembly and involved no substantial modification to the machine.

\section{CAPILLARY DEVELOPMENT}

Initially three ball/wedge standard bonding capillaries for $\mathrm{Au}$ wire bonding were examined to establish their suitability for ultrasonic Al ball/wedge bonding. All three capillaries gave good ball bonds, although the concentricity of the wire with the bond varied according to the capillary face cone angle dimensions. The capillary wedge bonds, however, were poor and had little tolerance to variation of the welding parameters. When capillary wedge welding $\mathrm{Au}$ wires, a capillary face angle generally in excess of $8^{\circ}$ is used to deform the wire in order to assist wire separation without disrupting the wedge bond. Because Al wire is less malleable than gold such tools tend to sever the wire rather than weld it, see Figure 3. Previous work ${ }^{2}$ has shown that the best wedge/wedge bonds are achieved when ultrasonic welding $25 \mu \mathrm{m}$ diameter $\mathrm{Al}$ wires with a wedge tool having a long foot length and a flat face parallel to the wire. The longer foot length produces a larger bond area which in turn permits higher bond pull strengths at lower wire deformations. The tool face being parallel to the work does not excessively deform the wire when the weld energy is increased because the high pressure produced by the initial point contact of an angled tool face is avoided. These princi pals were used to design an 


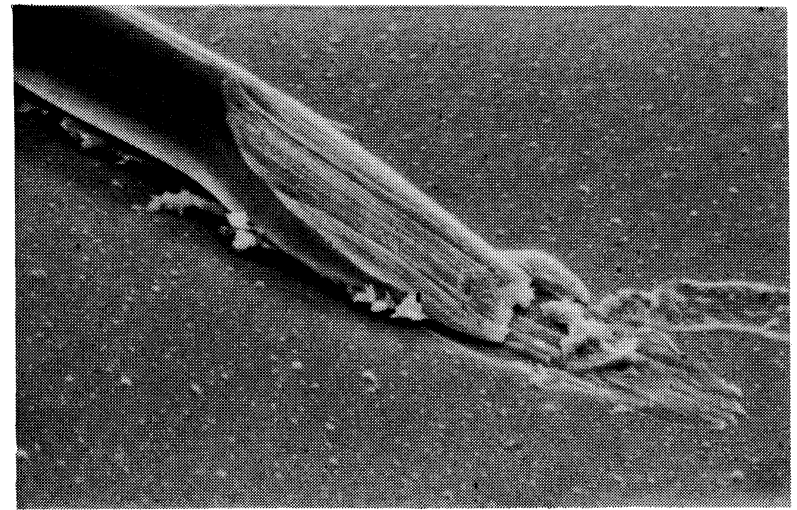

FIGURE 3 A capillary wedge bond between a $25 \mu \mathrm{m}$ diameter $\mathrm{Al}-1 \%$ Si wire and an $\mathrm{Al}$ thin film, made using a capillary designed for bonding Au wire.

experimental capillary in which a further consideration was the re-alignment of any axially offset balls prior to bonding. This is made difficult when the capillary has too shallow a cone and too large an included cone angle at the mouth of the wire feed hole. Experiments

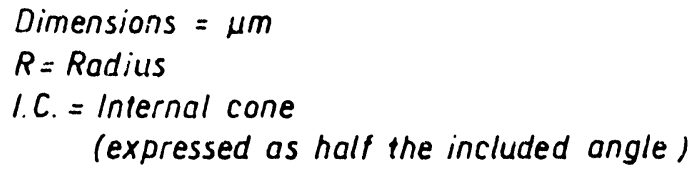

\section{$38 \pm 5$}

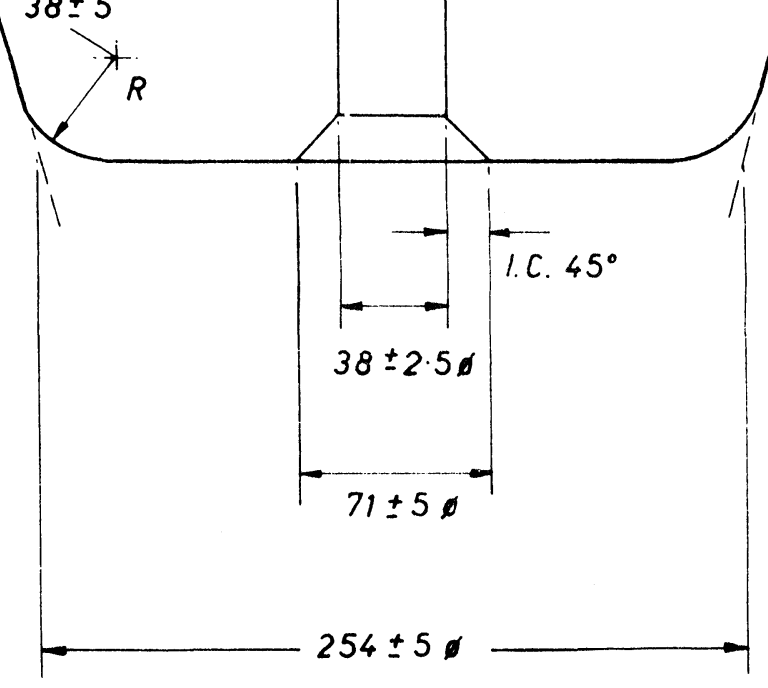

FIGURE $4 \quad \mathrm{Al}$ ball/wedge bonding capillary.

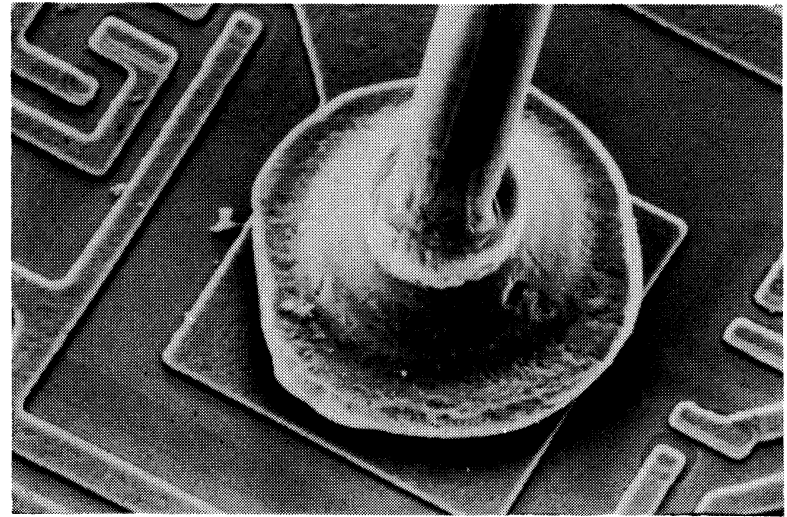

(a)

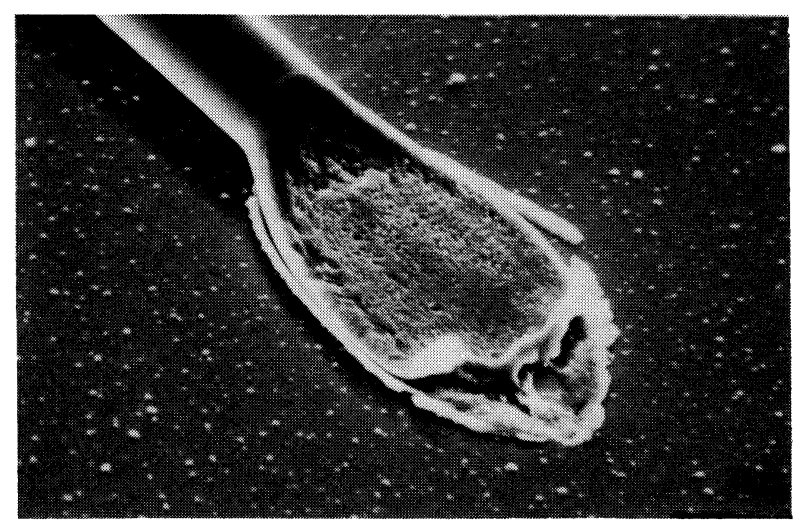

(b)

FIGURE 5 Good quality ball and wedge bonds made between $25 \mu \mathrm{m}$ diameter $\mathrm{Al}-1 \% \mathrm{Si}$ wire and $\mathrm{Al}$ thin film substrate.

(a) ball bond

(b) wedge bond

with capillaries having $90^{\circ}$ included cone angles showed that if the correct cone depth and diameter was employed good re-alignment of offset balls could be achieved. With this and former wedge tool experience in mind the capillary shown in Figure 4 was designed and manufactured for ultrasonic ball/wedge bonding $25 \mu \mathrm{m}$ dia $\mathrm{Al}$ wires. Good quality $\mathrm{Al}$ ball and wedge bonds made with the experimental capillary are shown in Figure 5. Ball re-alignment and the quality of the wedge bonds was considerably improved with the experimental capillary and therefore it was used for the welding trials.

\section{WELDING TRIALS}

Al-1\% Si wire (tensile strength $140 \mathrm{mN}$ ) was ultrasonic ball/wedge bonded to $\mathrm{Al}$ thin films, $\mathrm{Pd}-\mathrm{Ag}$ thick films and Au flashed Kovar. 
Preliminary work indicated that a bond time of $30 \mathrm{~ms}$ was satisfactory for both ball and wedge bonds. A bonding force of $300 \mathrm{mN}$ was used for all the ball bonds, and for the capillary wedge bonds to the $\mathrm{Al}$ thin films. The wedge bonds to the Pd-Ag thick films and $\mathrm{Au}$ flashed Kovar were made at $400 \mathrm{mN}$. The ultrasonic vibration amplitude is the parameter most likely to vary in practice and therefore this was studied in more detail. The amplitude was varied in $0.1 \mu \mathrm{m}$ steps (as measured free standing at end of the transducer horn) over a range which produced welds within established acceptance limits.

The acceptance limits for ball bonds were a minimum shear strength of $200 \mathrm{mN}$ and a maximum bond spread of $4 \times$ the wire dia. For the wedge bonds the limits were a minimum $30^{\circ}$ pull strength of $35 \mathrm{mN}$ ( $25 \%$ of wire tensile strength) and a maximum bond spread of $2.5 \times$ the wire dia.

\subsection{Al Thin Films}

For ball bonds made at the above time and force, the optimum vibration amplitude was $0.7 \mu \mathrm{m}$ with a tolerance of $\simeq_{-30}^{+40} \%$, see Table I. A histogram, Figure 6, for a sample of 100 bonds made at $0.7 \mu \mathrm{m}$ amplitude, shows a strength range of 300 to $550 \mathrm{mN}$. These values, although considered acceptable, do not give a true indication of the bond strength since in almost every instance, especially where the lower strengths were recorded, the shear failure occurred at the $\mathrm{Al}$ film/substrate interface.

A number of ball bonds were subjected to a vertical pull test. In every case the wire failed above the ball. The average failure force was $76 \mathrm{mN}$ (range 72 to $80 \mathrm{mN}$ ) which is more than $50 \%$ of the parent wire tensile strength (130 to $140 \mathrm{mN}$ ). The reason for the reduction is strength is that the wire is annealed during the ball forming operation.

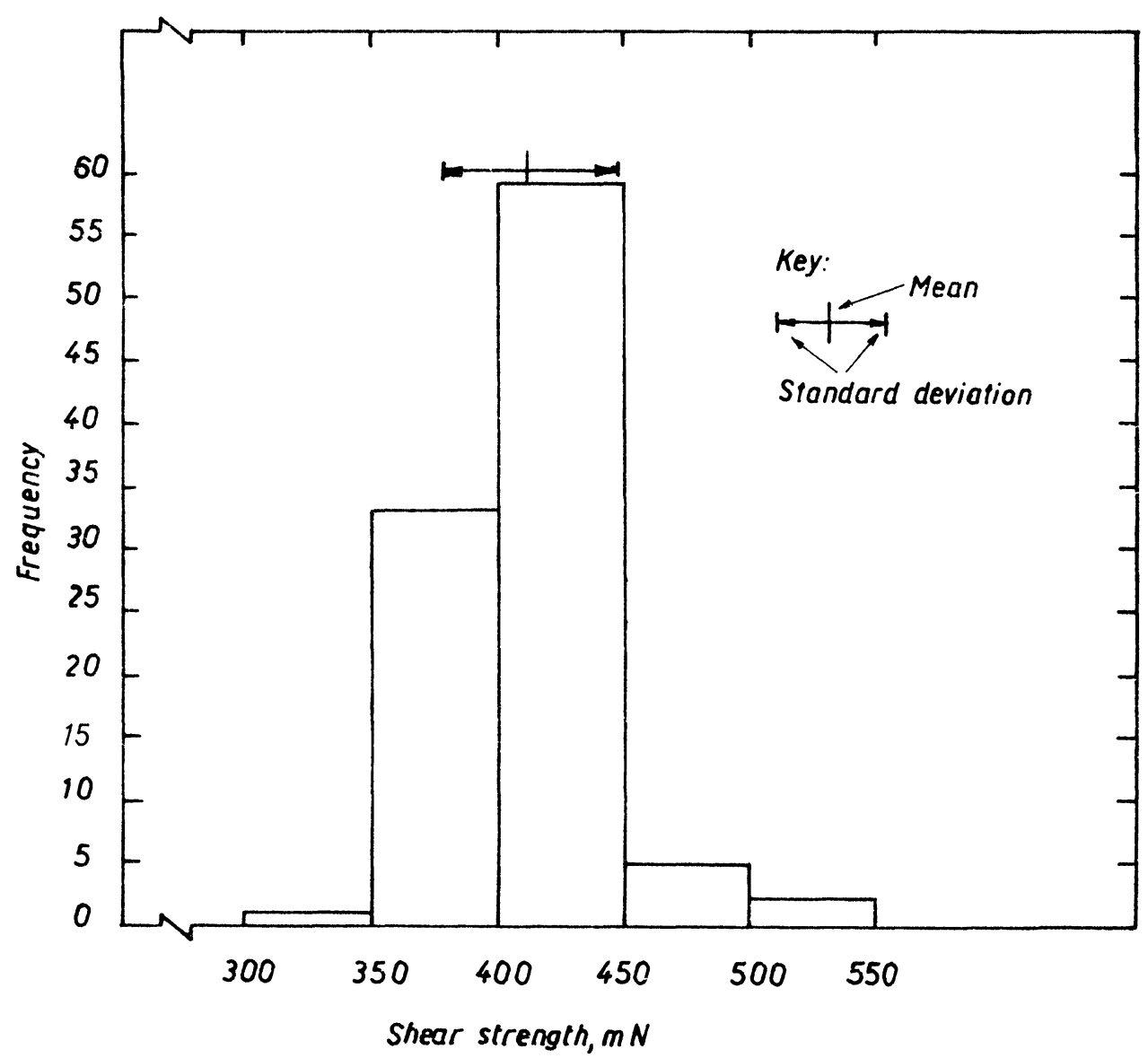

FIGURE 6 The strength distribution of $100 \mathrm{Al}-1 \% \mathrm{Si}$ ball bonds to $\mathrm{Al}$ thin film substrate. Optimum vibration amplitude $0.7 \mu \mathrm{m}$, weld time $30 \mathrm{~ms}$, weld force $300 \mathrm{mN}$. 

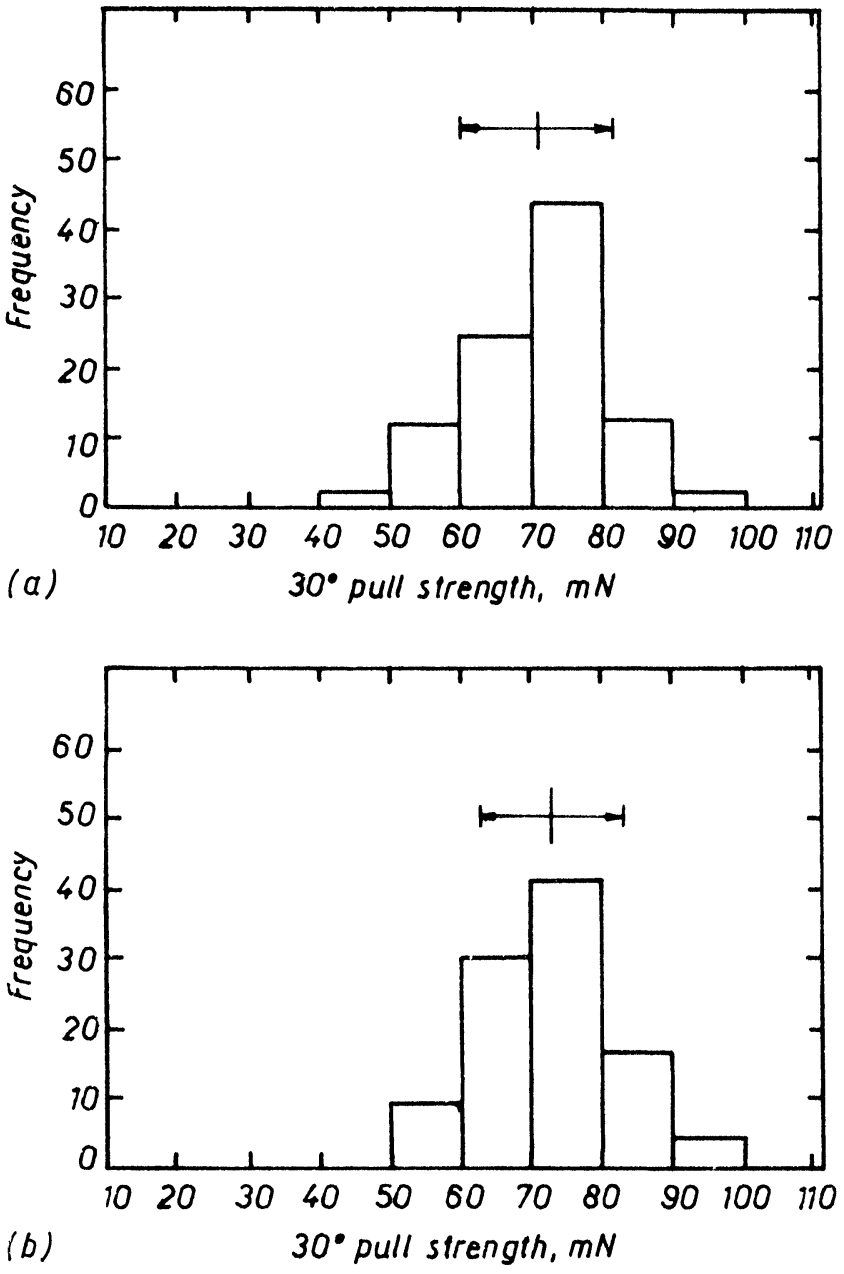

FIGURE 7 Strength distributions of $100 \mathrm{Al}-1 \%$ Si wire wedge bonds to $\mathrm{Al}$ thin film substrate. Optimum vibration amplitude $1.2 \mu \mathrm{m}$, weld time $30 \mathrm{~ms}$, weld force $300 \mathrm{mN}$.
(a) parallel
(b) transverse vibrations

TABLE I

Optimum vibration amplitude and tolerance established when ball bonding $25 \mu \mathrm{m}$ diameter $\mathrm{Al}-1 \% \mathrm{Si}$ wires to various films (weld time $30 \mathrm{~ms}$, weld force $300 \mathrm{mN}$ ).

\begin{tabular}{llll}
\hline & $\begin{array}{l}\text { Optimum } \\
\text { vibration } \\
\text { amplitude* } \\
\text { Film }\end{array}$ & \multicolumn{2}{l}{$\begin{array}{l}\text { Vibration } \\
\text { amplitude } \\
\text { range }\end{array}$} \\
\hline Al thin film & 0.7 & $\mu \mathrm{m}$ & $\%$ \\
\hline Pd-Ag thick film & 1.1 & 0.5 & +40 \\
& & 0.5 & +20 \\
Au flashed Kovar & 1.2 & 0.7 & +25 \\
\hline
\end{tabular}

*The optimum vibration amplitude was taken as the nearest $0.1 \mu \mathrm{m}$ magnitude in the middle of the acceptable vibration amplitude range.

${ }^{+}$Results based on a minimum bond shear strength of $200 \mathrm{mN}$ and a maximum weld spread of $100 \mu \mathrm{m}$.

When making the capillary wedge bonds the vibration amplitude which was most suited to both directions of vibration is $1.2 \mu \mathrm{m}$ (see Table II) producing an amplitude tolerance of $\simeq_{-30}^{+17} \%$ when the vibrations are parallel, $\simeq{ }_{17}^{40} \%$ when transverse, which therefore gives a tolerance of $\pm 17 \%$ when bonding through $360^{\circ}$. The bond strength histograms, Figure 7, for a sample of 100 bonds made at the $1.2 \mu \mathrm{m}$ amplitude show strengths ranging between 40 and $100 \mathrm{mN}$ for parallel vibrations and 50 to $100 \mathrm{mN}$ for transverse vibrations. In both instances the majority of strengths fall in the 60 to $80 \mathrm{mN}$ range.

\section{$4.2 \quad P d$-Ag Thick Films}

The optimum vibration amplitude for ball bonds made at the selected bonding time and force was

TABLE II

Optimum vibration amplitude and tolerance established when capillary wedge bonding $25 \mu \mathrm{m}$ diameter Al-1\% $\mathrm{Si}$ wires to various films (weld time $30 \mathrm{~ms}$ ).

\begin{tabular}{|c|c|c|c|c|c|c|c|c|}
\hline \multirow[b]{2}{*}{ Film } & \multirow[b]{2}{*}{$\begin{array}{l}\text { Bonding } \\
\text { force } \\
\mathrm{mN}\end{array}$} & \multirow{2}{*}{$\begin{array}{l}\text { Optimum } \\
\text { vibration } \\
\text { amplitude } \\
\mu \mathrm{m}\end{array}$} & \multirow[b]{2}{*}{ Parallel } & \multirow{2}{*}{$\begin{array}{l}\mu \mathrm{m} \\
\text { Transverse }\end{array}$} & \multicolumn{4}{|c|}{ Vibration amplitude range $^{+}$} \\
\hline & & & & & $\begin{array}{l}\text { Through }{ }^{++} \\
360^{\circ}\end{array}$ & Parallel & $\begin{array}{l}\% \\
\text { Transverse }\end{array}$ & $\begin{array}{l}\text { Through }{ }^{++} \\
360^{\circ}\end{array}$ \\
\hline Al thin film & 300 & 1.2 & 0.6 & 0.7 & 0.4 & $\begin{array}{l}+17 \\
-30\end{array}$ & $\begin{array}{l}+40 \\
-17\end{array}$ & \pm 17 \\
\hline Pd-Ag thick film & 400 & 1.2 & 0.3 & 0.3 & 0.3 & \pm 12 & \pm 12 & \pm 12 \\
\hline Au flashed Kovar & 400 & 1.5 & 0.3 & 0.4 & 0.3 & $\begin{array}{l}+10 \\
-13 \\
\end{array}$ & $\begin{array}{l}+20 \\
-7 \\
\end{array}$ & $\begin{array}{l}+10 \\
-7\end{array}$ \\
\hline
\end{tabular}

+ Results based on a minimum bond pull strength of $35 \mathrm{mN}$ and a maximum weld spread of $62.5 \mu \mathrm{m}$.

${ }^{++}$Results based on a vibration amplitude range suitable for both parallel and transverse ultrasonic vibrations. 
$1.1 \mu \mathrm{m}$, see Table I. Acceptable bonds can be made over an amplitude tolerance range of $\simeq+20 \%$ to $-25 \%$ from the optimum. The strength distribution of 100 shear tested bonds made at these optimum conditions extended from 450 to $800 \mathrm{mN}$ and averaged $620 \mathrm{mN}$. These strengths compared favourably with those previously achieved ${ }^{3}$ when ultrasonic $\mathrm{Au}$ ball bonding to Pd-Ag thick films where the maximum strength obtained was $580 \mathrm{mN}$ and the minimum $420 \mathrm{mN}$ over a range of optimised conditions.

The optimum vibration amplitude for capillary wedge bonds $\simeq 1.3 \mu \mathrm{m}$, with a tolerance of $\simeq \pm 12 \%$ for vibrations in both parallel and transverse vibrations (see Table II) and it is assumed that this will also apply when bonding through $360^{\circ}$. The tolerance to vibration amplitude may well be improved by using a shorter weld time. Previous experience $e^{3,4}$ when wedge/wedge bonding $\mathrm{Al}$ wires to Pd-Ag thick films has shown that a wider tolerance to vibration amplitude can be achieved using a $5 \mathrm{~ms}$ weld time. For both the parallel and transverse vibrations the $1.2 \mu \mathrm{m}$ amplitude produced a strength range of 50 to $100 \mathrm{mN}$ (average $75 \mathrm{mN}$ ) for a sample of 100 bonds. Although the tolerance to ultrasonic vibration amplitude is slightly less $( \pm 12 \%)$ than that established when making the wedge bonds to $\mathrm{Al}$ thin film $( \pm 17 \%)$ the bulk strength test results were very similar.

\subsection{Au Flashed Kovar}

The optimum vibration amplitude when making ball bonds was $1.2 \mu \mathrm{m}$ and the tolerance for acceptable welds, $\simeq+35 \%$ to $-25 \%$ (see Table I). A shear test sample of 100 bonds made at the optimum vibration amplitude, gave a strength range of 250 to $550 \mathrm{mN}$ (average $400 \mathrm{mN}$ ). These strengths are similar to those achieved on the Al thin films but are much lower than those achieved on the Pd-Ag thick film material. The lower strengths in this instance are not due to failure of the gold plating, but could be due either to the surface finish or alternatively to the use of a nonoptimised welding force and time. Nevertheless, in relation to the $\mathrm{Al}$ wire tensile strength $(\simeq 135 \mathrm{mN})$ the minimum weld shear strength of $250 \mathrm{mN}$ is considered acceptable.

Table II shows that when capillary wedge bonding to Au flashed Kovar the optimum amplitude for the time force studies was $1.5 \mu \mathrm{m}$ with a tolerance of $\simeq+10 \%$ to $-13 \%$ when the vibrations are parallel, $\simeq+20 \%$ to $-7 \%$ when the vibrations were transverse and hence $\simeq+10 \%$ to $-7 \%$ when bonding through $360^{\circ}$. For both parallel and transverse vibrations at the $1.5 \mu \mathrm{m}$ amplitude, the bond strength range for a 100 bond sample was between 40 and $110 \mathrm{mN}$, (average $75 \mathrm{mN}$ ). This strength range is very similar to the ranges achieved during the bulk strength tests of the wedge bonds to both the $\mathrm{Al}$ thin film and Pd-Ag thick film substrates.

\section{CONCLUSIONS}

Equipment employing an electric arc and an inert gas shield has been developed for forming balls on the end of $25 \mu \mathrm{m}$ diameter $\mathrm{Al}$ wires to enable $\mathrm{Al}$ bdll/wedge bonding. This equipment is easily incorporated onto standard ultrasonic Au wire ball/wedge welding machines. Ball and capillary wedge bonds of good strength were made with $25 \mu \mathrm{m}$ diameter $\mathrm{Al}-1 \% \mathrm{Si}$ wire to $\mathrm{Al}$ thin films, Pd-Ag thick films and Au flashed Kovar. The capillary wedge bond is considerably improved by using a flat faced capillary which is parallel to the work.

\section{ACKNOWLEDGEMENTS}

This work was carried out with the support of the United Kingdom, Ministry of Defence, DCVD. The help and assistance of the Design Authority, Mr B. Arthur, RSRE, Malvern is appreciated.

The authors would also like to acknowledge the work of the following colleagues: Messrs A. W. Carter, R. G. Clements and D. A. Edson.

\section{REFERENCES}

1. D. Baker, and I. E. Bryan, "An improved form of thermocompression bond," J. Appl. Phys. (GB), 16, $867 \mathrm{ff}, 1965$.

2. C. J. Dawes, "The effect of tool shape when ultrasonic wire welding." Proc. Int. Microelectronics Conf. Brighton, England, October 1977.

3. K. I. Johnson, M. H. Scott, and D. A. Edson, "Ultrasonic wire welding, Part II-Ball-Wedge wire welding." Solid State Technol., pp. 91-95, April 1977.

4. K. I. Johnson, M. H. Scott, and D. A. Edson, "Ultrasonic wire welding, Part I-Wedge-Wedge bonding of aluminium wires." Solid State Technol., pp. 50-56, March 1977. 

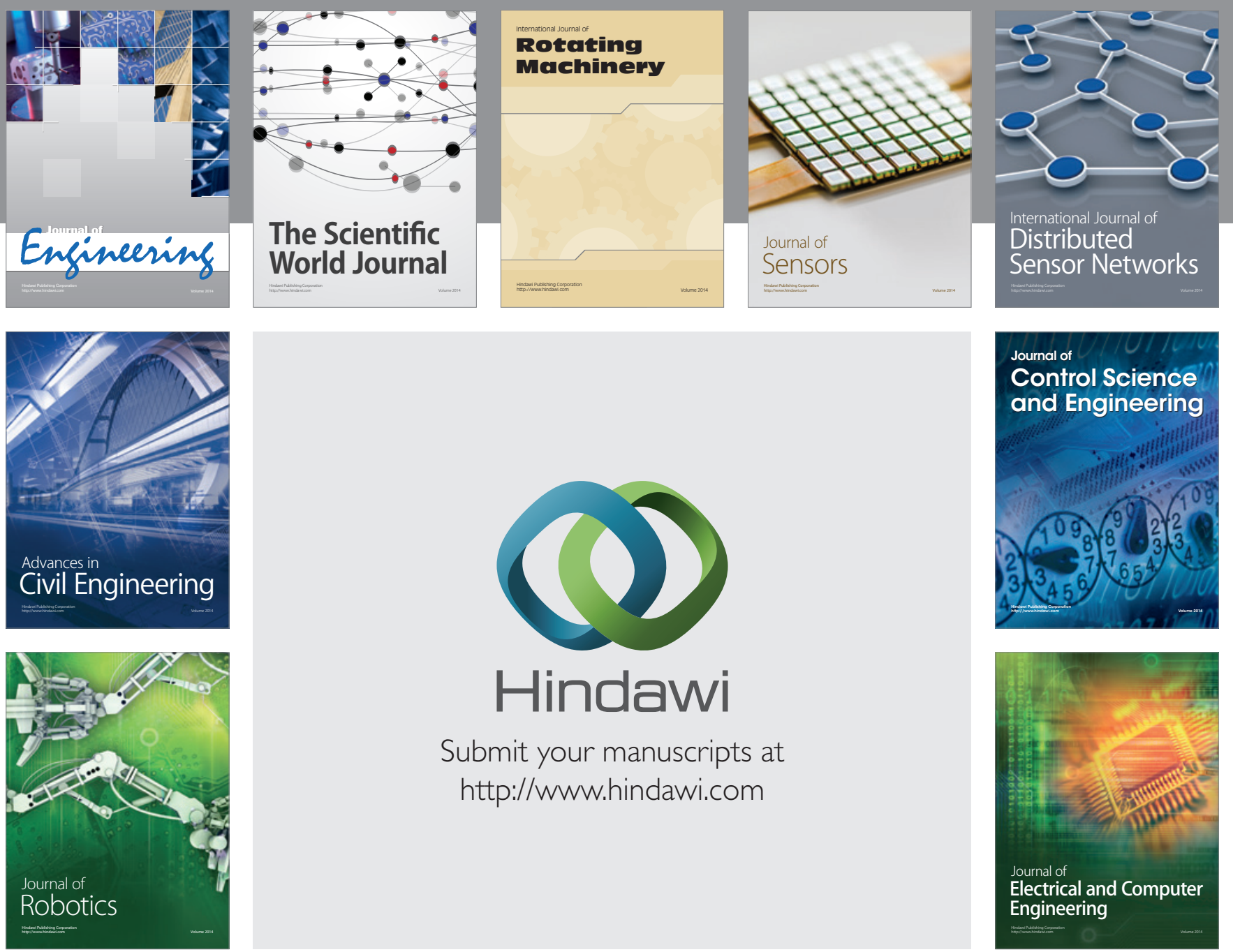

Submit your manuscripts at

http://www.hindawi.com
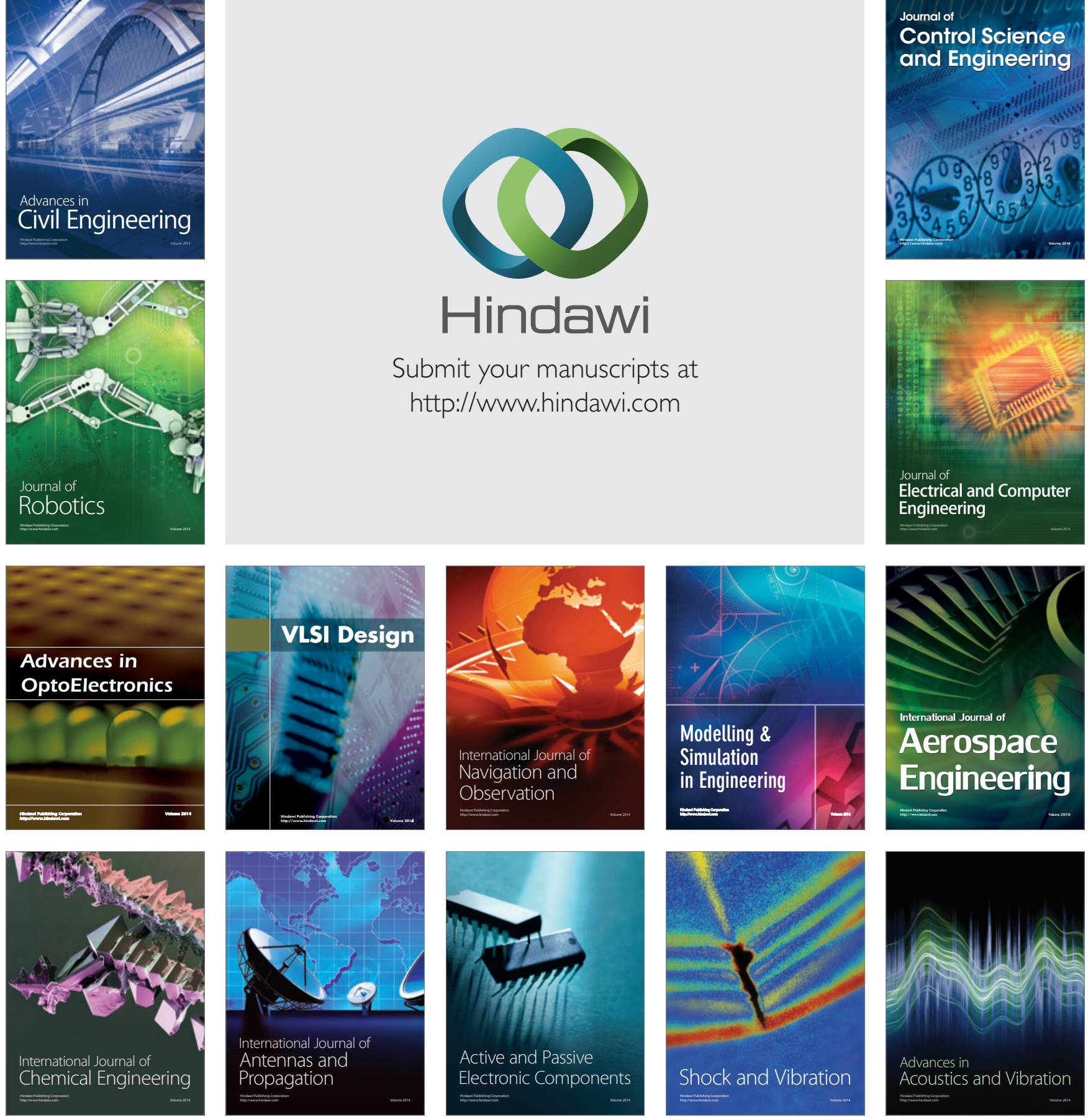